\title{
Novel use of the Nexfin HD monitor for hemodynamic management during electroconvulsive therapy in a patient with an unrepaired abdominal aortic aneurysm
}

\author{
Rosie Earle, BSc $\cdot$ Himat Vaghadia, MBBS • \\ Andrew Sawka, MD
}

Received: 21 January 2015/Accepted: 27 January 2015/Published online: 6 February 2015

(c) Canadian Anesthesiologists' Society 2015

\section{To the Editor}

Herein, we report the novel use of the Nexfin HD monitor (BMEYE, Amsterdam, The Netherlands) - now available as the ClearSight system (Edwards Lifesciences Corp, Irvine, CA, USA) - for hemodynamic management during electroconvulsive therapy (ECT) for the treatment of depression in a patient with an unrepaired abdominal aortic aneurysm (AAA). The Nexfin device uses photoplethysmographic technology to provide continuous noninvasive finger-cuff-based monitoring of blood pressure (BP), heart rate (HR), stroke volume, and cardiac output. ${ }^{1}$

Electroconvulsive therapy is commonly used for the treatment of several psychiatric conditions. ${ }^{2}$ The electrical activity it produces is known to cause a rapid and significant sympathetic discharge that can increase HR and BP up to $20 \%$ and $40 \%$, respectively. ${ }^{2,3}$ Theoretically, these changes increase the risk of rupture of a an unrepaired AAA. ${ }^{2}$ Noninvasive BP monitoring is usually performed intermittently via a conventional BP cuff, which may result in undiagnosed extremes of BP between the intermittent measurements. Continuous BP monitoring in patients with an unrepaired AAA allows for immediate recognition and correction of dangerous hypertension or tachycardia, ${ }^{2-4}$ but it typically requires placement of an invasive arterial catheter, which may be time consuming and induce some rare complications. ${ }^{5}$ Currently, there is little published information on the hemodynamic management and monitoring of patients with an unrepaired AAA who require ECT.

R. Earle, BSc $(\bowtie) \cdot$ H. Vaghadia, MBBS · A. Sawka, MD

Department of Anesthesia, Vancouver Coastal Health,

Vancouver, BC, Canada

e-mail: earle.rk@gmail.com
With the patient's consent, we report the case of a 79-yrold female with bipolar disorder who required two to three ECT procedures per week. She had a history of an unrepaired 5.5-cm AAA, stable coronary artery disease, hypertension, dyslipidemia, and mild renal insufficiency. Her ejection fraction was $55 \%$. We elected to proceed with ECT using the Nexfin device for continuous BP monitoring. 4

After an intravenous catheter and standard monitors were placed and with the patient supine, the finger cuff of the Nexfin device was placed around the patient's left hand index finger. A loading dose of esmolol $1 \mathrm{mg} \cdot \mathrm{kg}^{-1} i v$ was administered, followed by a further dose of $0.5 \mathrm{mg} \cdot \mathrm{kg}^{-1}$ to achieve a HR of approximately 50 beats $\cdot \min ^{-1}$ and a systolic BP of $110 \mathrm{mmHg}$, as measured by a conventional BP cuff. General anesthesia was induced with methohexital $1.2 \mathrm{mg} \cdot \mathrm{kg}^{-1}$, and then, succinylcholine $0.7 \mathrm{mg} \cdot \mathrm{kg}^{-1}$ was administered. This resulted in an expected decrease in systolic BP (Figure). During the ECT procedure, BP and HR were continuously monitored with Nexfin. The patient's blood pressure did not spike during or after the ECT stimulus, although there was a transient loss (i.e., artifact) of the Nexfin signal for $<20 \mathrm{sec}$, which may be a newly reported observation that requires further investigation (Figure). Post induction, the Nexfin monitor indicated relatively low systolic BPs $(69-85 \mathrm{mmHg})$. The patient tolerated the ECT well and was found to be hemodynamically stable both immediately postoperatively and on follow-up the next day.

Currently, there are no guidelines for the clinical management of patients with an unrepaired AAA who require ECT, although some authors suggest that ECT may be performed safely in this population. ${ }^{4}$ A retrospective review of eight patients with an unrepaired AAA who underwent ECT had no AAA-related complications or 

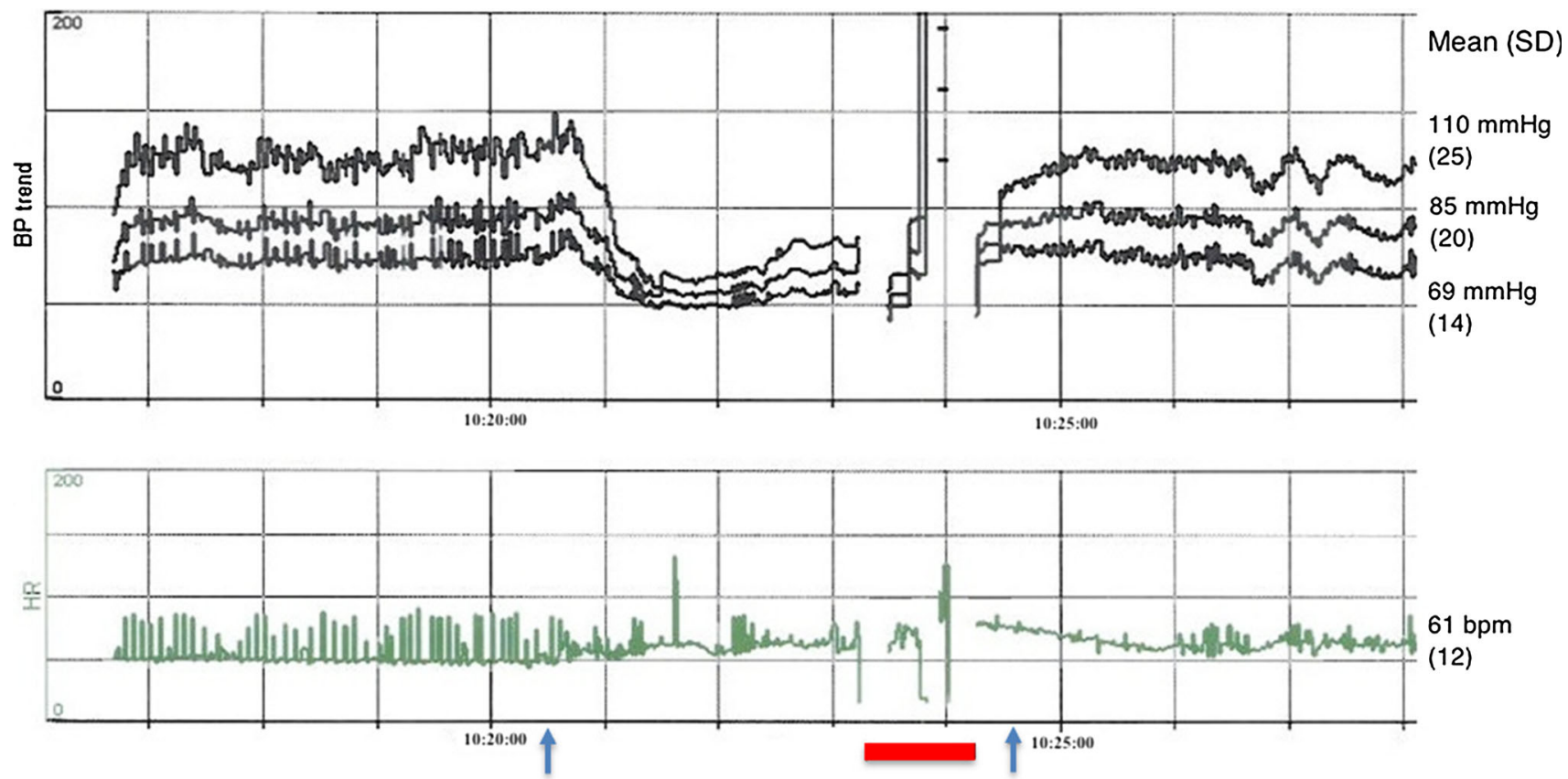

Figure Blood pressure (BP) and heart rate (HR) output from the Nexfin HD monitor. The arrows outline the induction of and emergence from anesthesia. The red bar represents the duration of the electroconvulsive therapy (ECT). Importantly, there are some

expansion of the aneurysm beyond the expected background rate. ${ }^{4}$ Our case illustrates that the Nexfin HD monitor can be used as a safe method for continuous blood pressure monitoring in patients with comorbid cardiac conditions receiving ECT. Further research with the use of the Nexfin device in this population will help to determine the safety and efficacy of this approach and clarify the transient loss of signal during ECT.

Acknowledgment This work was supported by Internal Departmental Funds.

\section{References}

1. Thiele $R H$, Bartels $K$, Gan TJ. Inter-device differences in monitoring for goal-directed fluid therapy. Can J Anesth 2015; DOI: $10.1007 / \mathrm{s} 12630-014-0265-\mathrm{z}$. monitoring artifacts during the ECT period, but these are of shorter duration than the usual time period between conventional intermittent blood pressure cuff measurements

2. Geersing $P G$, Bulte CS, Viersen VA, et al. Beat-to-beat hemodynamic monitoring during electroconvulsive therapy. J ECT 2011; 27: 189-91.

3. Kurup $V$, Ostroff $R$. When cardiac patients need ECT-challenges for the anesthesiologist. Int Anesthesiol Clin 2012; 50: 128-40.

4. Mueller PS, Albin SM, Barnes RD, Rasmussen KG Jr. Safety of electroconvulsive therapy in patients with unrepaired abdominal aortic aneurysm: report of 8 patients. J ECT 2009; 25: 165-9.

5. Wallach $S G$. Cannulation injury of the radial artery: diagnosis and treatment algorithm. Am J Crit Care 2004; 13: 315-9. 